\title{
Evaluation of Industrial Compensation to Cardiologists in 2015
}

\author{
Muhammad Shahzeb Khan, MD ${ }^{\mathrm{a}, *}$, Tariq Jamal Siddiqi, MD ${ }^{\mathrm{b}}$, Kaneez Fatima, MD ${ }^{\mathrm{b}}$, Haris Riaz, MD , \\ Faisal Khosa, MD, MBA ${ }^{\mathrm{d}}$, Warren J. Manning, MD ${ }^{\mathrm{e}}$, and Richard Krasuski, MD
}

\begin{abstract}
The categorization and characterization of pharmaceutical and device manufacturers or group purchasing organization payments to clinicians is an important step toward assessing conflicts of interest and the potential impact of these payments on practice patterns. Payments have not previously been compared among the subspecialties of cardiology. This is a retrospective analysis of the Open Payments database, including all installments and payments made to doctors in the calendar year 2015 by pharmaceutical and device manufacturers or group purchasing organization. Total payments to individual physicians were then aggregated based on specialty, geographic region, and payment type. The Gini Index was further employed to calculate within each specialty to measure income disparity. In 2015 , a total of $\$ 166,089,335$ was paid in 943,744 payments (average $\$ 175.00$ per payment) to cardiologists, including 23,372 general cardiologists, 7,530 interventional cardiologists, and 2,293 cardiac electro-physiologists. Payments were mal-distributed across the 3 subspecialties of cardiology $(p<0.01)$, with general cardiology receiving the largest number (73.5\%) and total payments $(62.6 \%)$ and cardiac electrophysiologists receiving significantly higher median payments $(\$ 1,662$ vs $\$ 361$ for all cardiologists; $p<0.01)$. The Medtronic Company was the largest single payer for all 3 subspecialties. In conclusion, pharmaceutical and device manufacturers or group purchasing organizations continue to make substantial payments to cardiac practitioners with a significant variation in payments made to different cardiology subspecialists. The largest number and total payments are to general cardiologists, whereas the highest median payments are made to cardiac electrophysiologists. The impact of these payments on practice patterns remains to be examined. (C) 2017 Elsevier Inc. All rights reserved. (Am J Cardiol 2017;120:2294-2298)
\end{abstract}

The 2010 Affordable Care Act contained a list of provisions including the Physicians Payment Sunshine Act, which served to facilitate the transparency of relationships between medical practitioners and the industry. In essence (subject to certain qualifications such as sample medications, discounts, and rebates), the payments made by the medical industry to medical practitioners and hospital staff, in terms of gifts, research funding, medical education, or consultancy, must be reported to the Centers for Medicare and Medicaid Services (CMS), the database for the Act. ${ }^{1}$ As many as $94 \%$ of US physicians maintain some financial relationships with the industry. ${ }^{2,3}$ Driven by public interest in the disclosure of the extent of these financial relationships, the Sunshine Act is an important step in both quantifying these ties and shedding light on potential conflicts of interest and influence of the industry's payments on practice patterns. ${ }^{4}$ Payments made

\footnotetext{
${ }^{a}$ Internal Medicine, John H. Stroger Jr. Hospital of Cook County, Chicago, Illinois; 'bnternal Medicine, Dow University of Health Sciences, Karachi, Pakistan; ${ }^{\mathrm{c} C a r d i o l o g y}$, Cleveland Clinic, Cleveland, Ohio; ${ }^{\mathrm{d}}$ University of British Columbia, Vancouver General Hospital, Vancouver, British Columbia,

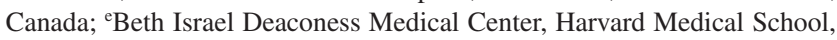
Boston, Massachusetts; and ${ }^{\mathrm{f} C a r d i o l o g y, ~ D u k e ~ U n i v e r s i t y, ~ D u r h a m, ~ N o r t h ~}$ Carolina. Manuscript received July 22, 2017; revised manuscript received and accepted September 1, 2017.

See page 2297 for disclosure information.

*Corresponding author: Tel: 4042593490; fax: +3128646000 .

E-mail address: shahzebkhan@gmail.com (M.S. Khan).
}

to practitioners and medical staff by industry or group purchasing organizations are all reported and filed in the Act's database, which are publicly posted every year. We sought to comparatively analyze the compensation received by cardiologists of different subspecialties.

\section{Methods}

This study is an analysis of the Open Payments database, which was made accessible through the publicly available website for the CMS (https://www.cms.gov/openpayments/). ${ }^{5}$ All installments and payments made to doctors between January 1, 2015, and December 31, 2015, by US pharmaceutical or device companies and group purchasing associations were extracted on May 11, 2017.

We used 3 filters separately (i.e., "cardiac electrophysiology," "interventional cardiology," and "cardiovascular disease") in the physician specialty column of the Open Payments database to separate the raw data according to specialty which was eventually downloaded. Although we extracted the data for advanced heart failure and transplantation as well, these data were not used in analyses and comparisons as their sample size was very small $(n=7)$. Disputed payments were excluded from subsequent analysis.

To determine the income distribution of the cardiology subspecialties, we employed the Gini Index. The Gini Index analyzes the ratio of the area around a Lorenz Curve and graphically shows these data to ascertain inequality in wealth distribution. ${ }^{6}$ A Gini Index of " 0 " signifies that payments are 
equally distributed, whereas an index of "1" signifies that all payments were provided to 1 person. We calculated the Gini Index using Microsoft Excel 2016 (Microsoft Corporation, Redmond, Washington). We also utilized SPSS Statistics (v23.0, International Business Machines, Chicago, Illinois) to graphically represent the findings via models.

The Gini Index calculations were aggregated by subspecialty and CMS region. The CMS regions are categorized by the location of the 10 regional offices and their geographic coverage as follows: (1) Atlanta: Kentucky, Tennessee, North Carolina, South Carolina, Georgia, Alabama, Mississippi, and Florida; (2) Boston: Maine, New Hampshire, Vermont, Massachusetts, Rhode Island, and Connecticut; (3) Kansas City: Nebraska, Iowa, Kansas, and Missouri; (4) New York: New York, New Jersey, Puerto Rico, and Virgin Islands; (5) San Francisco: California, Nevada, Arizona, Hawaii, Guam, and Armed Forces Pacific; (6) Philadelphia: Pennsylvania, West Virginia, Virginia, Delaware, Maryland, and District of Columbia; (7) Dallas: New Mexico, Oklahoma, Texas, Arkansas, and Louisiana; (8) Denver: Montana, North Dakota, South Dakota, Wyoming, Utah, and Colorado; (9) Seattle: Washington, Oregon, Idaho, and Alaska; and (10) Chicago: Minnesota, Wisconsin, Illinois, Indiana, Ohio, and Michigan.

The total payments made to each physician by physician profile ID were calculated. Median payments per physician, along with interquartile range and the mean payments for each physician group with the SD, as well as minimum and maximum payments, were calculated. Data were then aggregated by subspecialty. The range for single payments and mean aggregate installments by payment type were also determined. Furthermore, the 3 main organizations with the largest payments to each specialty and overall cardiology field were determined. The Kruskal-Wallis test was used to determine if the difference in payments across the subspecialties was significant, whereas the Dunn's Nonparametric Comparison was used to compare individual pairs of subspecialties. A p value of less than 0.05 was considered significant.

\section{Results}

During the 2015 reporting period, a total of $\$ 166,089,335$ was paid with 943,744 payments (average $\$ 175$ per payment; median $\$ 361$ per payment) made to 33,195 cardiologists, including 23,372 general cardiologists (GCs), 7,530 interventional cardiologists (ICs), and 2,293 cardiac electrophysiologists (CEs). A total of $152(0.016 \%)$ payments in the database were marked as "disputed." GCs had the most disputed payments $(n=143 ; 0.02 \%)$, followed by CEs $(n=7$; $0.007 \%)$ and ICs $(n=2 ; 0.001 \%)$. Table 1 illustrates the general statistics of industrial compensation for all of cardiology and according to cardiology specialty. The largest group (GCs) received almost double the amount of total payments to all other subspecialties combined. Payments were significantly mal-distributed across the subspecialties $(\mathrm{p}<0.01)$, with the median CE payment nearly 10 times greater than that paid to ICs and 5 times greater than the median for the GCs. A distribution of individual payments by dollar range is displayed in Table 2. The vast majority $(96.3 \%)$ of individual payments were less than $\$ 1,000$, with only $0.08 \%$ of all payments above $\$ 10,000$.

Figure 1 shows the Gini Index based on the CMS region of each cardiology subspecialty. The regional Gini indices did not vary much, with the least calculated for cardiac electrophysiologists in Atlanta (0.76) to the most calculated for cardiac electrophysiologists in Seattle (0.97). For ease of understanding, we employed categories according to the "nature of payment." The distribution of payments across these categories

Table 1

General statistics of payments to all cardiologists and to individual cardiac subspecialists

\begin{tabular}{|c|c|c|c|c|}
\hline Statistics & $\begin{array}{l}\text { All cardiology } \\
(\mathrm{n}=33,195)\end{array}$ & $\begin{array}{l}\text { General cardiology } \\
(\mathrm{GC})(\mathrm{n}=23,372)\end{array}$ & $\begin{array}{l}\text { Cardiac electrophysiology } \\
\text { (CE) }(n=2,293)\end{array}$ & $\begin{array}{l}\text { Interventional cardiology } \\
\text { (IC) }(\mathrm{n}=7,530)\end{array}$ \\
\hline Mean, \$ (SD) & $4,579(35,495)$ & $4,585(34,053)$ & $13,336(104,532)$ & $4,189(31,379)$ \\
\hline Median, \$ & 361 & 387 & 1,662 & 175 \\
\hline Minimum,\$ & 1 & 1 & 7 & 5 \\
\hline Maximum,\$ & $4,395,652$ & $2,876,644$ & $4,395,652$ & $1,633,903$ \\
\hline Total, \$ & $166,089,335$ & $103,956,574(62.6 \%)$ & $30,588,739(18.4 \%)$ & $31,544,022(18.9 \%)$ \\
\hline IQR Low,\$ & 101 & 108 & 220 & 42 \\
\hline IQR high,\$ & 1,364 & 1,417 & 7,347 & 1,155 \\
\hline
\end{tabular}

Percentages represent the ratio of total payments to a cardiac sub-specialty to that of total payments to cardiologists.

$\mathrm{IQR}=$ interquartile range, $\mathrm{SD}=$ standard deviation.

Table 2

Distribution of single payment by dollar amount to each cardiac-subspecialty and in the overall cardiology field

\begin{tabular}{|c|c|c|c|c|}
\hline Dollar range & $\begin{array}{l}\text { All cardiology } \\
(\mathrm{n}=943,744)\end{array}$ & $\begin{array}{l}\text { General cardiology } \\
\quad(n=693,429)\end{array}$ & $\begin{array}{l}\text { Cardiac electrophysiology } \\
\qquad(\mathrm{n}=94,033)\end{array}$ & $\begin{array}{l}\text { Interventional cardiology } \\
\qquad(\mathrm{n}=156,282)\end{array}$ \\
\hline$<\$ 1,000$ & $909,140(96.3 \%)$ & $669,826(96.5 \%)$ & $88,074(93.6 \%)$ & $151,240(96.7 \%)$ \\
\hline$\$ 1,000-\$ 9,999$ & $33,875(3.6 \%)$ & $23,138(3.3 \%)$ & $5,824(6.1 \%)$ & 4,913 (3.1\%) \\
\hline$\$ 10,000-\$ 24,999$ & $557(0.059 \%)$ & $357(0.051 \%)$ & $107(0.1 \%)$ & $93(0.059 \%)$ \\
\hline Greater than $\$ 25,000$ & $172(0.018 \%)$ & $108(0.015 \%)$ & $28(0.029 \%)$ & $36(0.023 \%)$ \\
\hline
\end{tabular}

Percentages represent the ratio of total number of payments in each dollar range to that of total number of payments in each sub-specialty. 


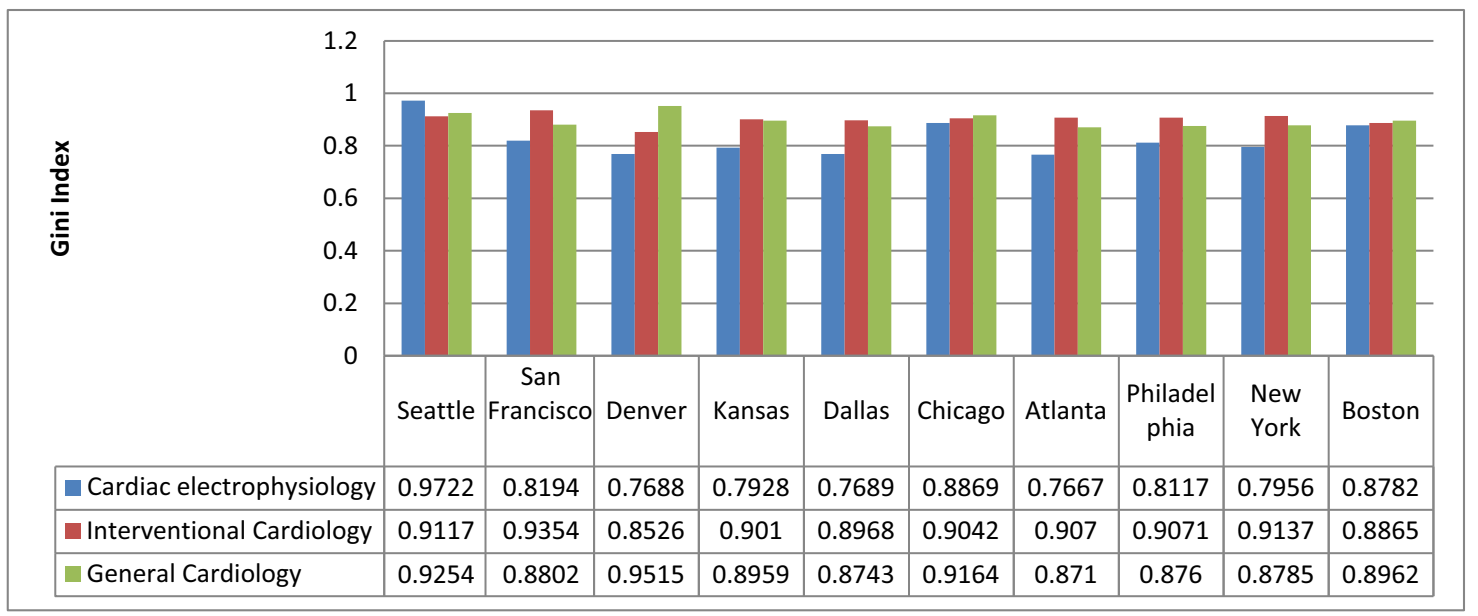

Figure 1. Gini Index by CMS region for each subspecialty.

Table 3

Distribution of payments by type of payment to each sub-specialty

\begin{tabular}{|c|c|c|c|c|c|c|}
\hline Category & \multicolumn{2}{|c|}{ General cardiology } & \multicolumn{2}{|c|}{ Cardiac electrophysiology } & \multicolumn{2}{|c|}{ Interventional cardiology } \\
\hline Compensation $^{1 *}$ & $43,376,377(41.7 \%)$ & 18,414 & $11,274,609(36.8 \%)$ & 5,824 & $10,335,392(32.7 \%)$ & 470 \\
\hline Compensation $^{3 \neq}$ & $182,545(0.1 \%)$ & 28 & $0(0.00 \%)$ & 0 & $15,016(0.04 \%)$ & 5 \\
\hline Consulting fee & $21,080,852(20.2 \%)$ & 6,492 & $4,896,807(16.0 \%)$ & 1,807 & $5,302,757(16.8 \%)$ & 1,615 \\
\hline $\begin{array}{l}\text { Current or prospective } \\
\text { ownership or } \\
\text { investment interest }\end{array}$ & $3,081,754(2.9 \%)$ & 33 & $2,328,100(7.61 \%)$ & 10 & $3,606,396(11.4 \%)$ & 14 \\
\hline Entertainment & $12,534(0.01 \%)$ & 282 & $5,145(0.016 \%)$ & 114 & $3,124(0.009 \%)$ & 94 \\
\hline Education & $761,497(0.7 \%)$ & 15,556 & $90,887(0.29 \%)$ & 1,337 & $157,815(0.5 \%)$ & 2,786 \\
\hline Food and Beverage & $15,726,681(15.1 \%)$ & 612,107 & $2,659,050(8.69 \%)$ & 75,725 & $4,123,105(13.05 \%)$ & 138,760 \\
\hline Gift & $9,315(0.001 \%)$ & 39 & $25(0.000081 \%)$ & 1 & $657(0.002 \%)$ & 8 \\
\hline Grant & $1,265,307(1.2 \%)$ & 316 & $621,343(2.0 \%)$ & 140 & $97,868(0.3 \%)$ & 20 \\
\hline Honoraria & $1,986,940(1.9 \%)$ & 715 & $132,950(0.4 \%)$ & 72 & $716,666(2.2 \%)$ & 270 \\
\hline
\end{tabular}

Percentages represent the ratio of payments under each type of payment to that of total payments to each sub-specialty.

* Compensation ${ }^{1}=$ for services other than consulting, including serving as faculty or as a speaker at a venue other than a continuing education program.

${ }^{\dagger}$ Compensation ${ }^{2}=$ for serving as faculty or as a speaker for a non-accredited and noncertified continuing education program.

${ }^{\ddagger}$ Compensation ${ }^{3}=$ for serving as faculty or as a speaker for an accredited or certified continuing education program.

is represented in Table 3. For all subspecialties, the largest number of payments was under the category "food and beverage." The top 3 companies (by sum total payments) that provided the greatest compensation for each subspecialty and the all cardiology field is displayed in Table 4. The Medtronic Company paid the highest compensation to all 3 subspecialties.

\section{Discussion}

The practice of industrial payments to medical practitioners is generally frowned upon by the public as it is perceived as an incentive for physicians to prescribe or utilize those companies' products instead of adopting the best and most costeffective strategies. In the period immediately after the passage of the 2010 Sunshine Act and before the first reporting of the Open Payments database, several large pharmaceutical companies and organizations initiated a reduction in payments to
Table 4

Top three companies that paid compensations to each sub-specialty and all cardiology

\begin{tabular}{llr}
\hline Specialty & \multicolumn{1}{c}{ Top 3 payers } & \multicolumn{1}{c}{ Total paid } \\
\hline All Cardiology & Medtronic Company & $\$ 22,583,949$ \\
& Janssen Pharmaceuticals & $\$ 11,080,525$ \\
& AstraZeneca Pharmaceuticals & $\$ 7,403,804$ \\
General Cardiology & Medtronic Company & $\$ 10,223,445$ \\
& Janssen Pharmaceuticals & $\$ 8,854,702$ \\
& AstraZeneca Pharmaceuticals & $\$ 7,403,804$ \\
Interventional Cardiology & Medtronic Company & $\$ 5,498,662$ \\
& Tendyne Holdings & $\$ 3,164,458$ \\
Cardiac Electrophysiology & Janssen Pharmaceutical & $\$ 2,225,823$ \\
& Medtronic Company & $\$ 6,861,842$ \\
& Boston Scientific Corporation & $\$ 6,531,278$ \\
& St. Jude Medical & $\$ 3,789,760$ \\
\hline
\end{tabular}


physicians. ${ }^{7}$ Despite this, our results indicate that close to $\$ 200$ million were distributed to about 35,000 cardiology practitioners in 2015, with an overwhelming majority of payments paid to GCs. Despite almost a million recorded payments, only $152(0.02 \%)$ were disputed. The extremely low percentage of disputes may be due to the accurate transparency in the dealings between the industry and the practitioners or may reflect the lack of initiative for dispute by practitioners. Even in this aspect, it was surprising to note that GCs had the highest number $(\mathrm{n}=143)$ of these disputes.

Although GCs received the largest number of payments, CEs had a significantly higher median payment. Cardiac electrophysiology is a relatively new field and is heavily dependent on new technology that is often expensive, ${ }^{8}$ as research and development costs are yet to be absorbed in sales. This young market with a large growth potential has enticed medical industries who value CE practitioners' involvement in helping them to develop and promote their products. ${ }^{9}$ Our results are similar to those of previous studies, where procedural interventionists received a larger amount of payment from the industry. ${ }^{3,10}$ The reason the high median payment did not extend to ICs with advances in treatment of structural heart disease is uncertain but may reflect the 2015 reporting year and the relative infancy of structural heart disease treatment (i.e., transcutaneous aortic valve replacement, MitralClip; Abbot laboratories [Lake Bluff, Illinois]) in 2015.

The vast majority (96\%) of the number of payments in all cardiology subspecialties were in the $<\$ 1,000$ bracket with only $0.08 \%$ of all payments above $\$ 10,000$. This is likely related to the largest number of payments in all subspecialties of cardiology being under the category of "food and beverages." The payments received by practitioners were not limited to basic compensation for services but included a myriad of other reasons. These payments may be potential financial conflicts of interest. Results from previous studies have demonstrated that physicians' decision making may change as a result of small gifts, meals, and large consulting payments. ${ }^{11,12}$

The Gini Index we employed is a measurement of income distribution ranging from 0 (signifying perfect equality) to 1 (perfect inequality). The Gini Index is generally interpreted comparatively via the simultaneous highlighting of several distinct groups. Our results showed a high Gini Index score of 0.76 to 0.97 irrelevant of the subspecialty and CMS region. This suggests that there are only a few cardiologists in each subspecialty and CMS region receiving a majority of the payments from pharmaceutical and device manufacturers or group purchasing organizations. It is plausible that highly valuable expertise about insights into very important medical products is not equally distributed and companies pay more for more useful insights.

The Medtronic Company paid the highest total amount to all cardiology subspecialties. Although Medtronic exclusively markets medical devices used by electrophysiologists and interventional physicians, we found it as the largest payer to GCs as well. This interesting finding could be attributed to the fact that Medtronic recently introduced a global noncommunicable disease initiative, a long-term strategic commitment to help treat chronic heart diseases-commonly treated under the care of GCs. ${ }^{13}$ Companies rely heavily on physicians to work with the industry to advance research and to translate ideas from the laboratories into practice. ${ }^{14}$ This, however, could also be viewed as a conflict of interest. For instance, a physician may be paid by a company to research and develop a new product. When that physician subsequently publishes a study in support of the product, other physicians may use or endorse the product based on the credibility of the research and its author, believing the research to be independent and unbiased. Such endorsement also facilitates royalties, which serves well in casting doubt as to the degree of bias in the study.

The impact of public reporting of physician payments on public perception has not been fully assessed. A patient's understanding of physician payments is generally limited. ${ }^{15}$ There are disparate subjective notions regarding this matter. Whereas some might perceive receiving payments from the industry as benign and do not harbor concerns, others may interpret this as an undue influence and grounds for bias. In a recent study Grady et al showed that a fraction of patients believed that the payments physicians received are a "personal matter." ${ }^{16}$ Other studies found that some patients demand full disclosure of financial relationships. ${ }^{17}$ The relationship between physicians and the medical industry is a complex but necessary one that needs to be monitored closely to remove any bias. Analyzing payments of subsequent years and comparing them with those of previous years such as ours can help understand this relationship better.

Our study has limitations. Incorrect payments were documented in the first year (2013) of the Sunshine Act, with data reported by 1,347 companies, of which 1,228 submitted at least one payment record with varying physician identifiers. ${ }^{1}$ As a result of such inaccuracies, $\$ 2.2$ billion worth of 2013 payments went unpublished..$^{18}$ For the second year (2014), algorithms were implemented by the CMS to confirm the physician data with additional sources; as a result, $98.8 \%$ of submitted payment information was successfully confirmed. ${ }^{19}$ Similar data for 2015 are unknown. Second, not all payments are required to be reported. Payments under $\$ 10$ are exempt from reporting. Finally, the data extracted for this study represent a limited period of time (2015).

\section{Disclosures}

Dr. Khosa is the recipient of the Canadian Association of Radiologists/Canadian Radiological Foundation Leadership Scholarship (2017). The authors have no relevant disclosures. There was no commercial funding for this study.

1. Agrawal S, Brennan N, Budetti P. The sunshine act-effects on physicians. N Engl J Med 2013;368:2054-2057.

2. Licurse A, Barber E, Joffe S, Cross C. The impact of disclosing financial ties in research and clinical care, a systematic review. JAMA Intern Med 2010;170:675-682.

3. Campbell EG, Gruen RL, Mountford J, Mountford J, Miller JG, Cleary $\mathrm{PD}$, Blumenthal D. A national survey of physician-industry relationships. N Engl J Med 2007;356:1742-1750.

4. Coyle SL, Ethics and Human Rights Committee, American College of Physicians-American Society of Internal Medicine. Physician-industry relations part 1: individual physicians. Ann Intern Med 2002;136:396402.

5. Centre for Medicare and Medicaid Services. General payment datadetailed dataset 2015 reporting year. Available at: https:// openpaymentsdata.cms.gov/browse. Accessed on May 11, 2017. 
6. Bellu' LG, Liberati P. The Gini Index. Rome, Italy: Food and Agriculture Organization of the United Nations; 2006.

7. As full disclosure nears, doctors' pay for drug talks plummets. Available at: http://www.propublica.org/article/as-full-disclosure -nears-doctors-pay-for-drug-talksplummets. Accessed on July 11, 2017.

8. Dimarco JP. Cardiac electrophysiology: a cost-effective approach. Clin Cardiol 1996;19:575-578.

9. Mentz RJ, Becker RC. Funding opportunities for clinical investigators in the early stages of career development in cardiovascular research. $J$ Thromb Thrombolysis 2013;36:527-532.

10. Kesselheim AS, Robertson CT, Siri K, Batra P, Franklin JM. Distributions of industry payments to Massachusetts physicians. N Engl J Med 2013;368:2049-2052.

11. Bekelman JE, Li Y, Gross CP. Scope and impact of financial conflicts of interest in biomedical research. JAMA 2003;289:454465.

12. Chren MM, Landefeld CS. Physicians' behavior and their interactions with drug companies. JAMA 1994;271:684-689.
13. Tackling noncommunicable disease. Available at: http://www .medtronic.com/innovation-au/borderless-NCD.html. Accessed on August 22, 2017.

14. Chatterji AK, Fabrizio KR, Mitchell W, Schulman KA. Physicianindustry cooperation in the medical device industry. Health Aff (Millwood) 2008;27:1532-1543.

15. Kao AC, Zaslavsky AM, Green DC, Koplan JP, Cleary PD. Physician incentives and disclosure of payment methods to patients. J Gen Intern Med 2001;16:181-188.

16. Grady C, Horstman E, Sussman JS, Hull SC. The limits of disclosure: what research subjects want to know about investigator financial interests. J Law Med Ethics 2006;34:592-599.

17. Tattersall MHN, Dimoska A, Gan K. Patients expect transparency in doctors' relationships with the pharmaceutical industry. Med J Aust 2009;190:65-68.

18. Santhakumar S, Adashi EY. The Physician Payment Sunshine Act: testing the value of transparency. JAMA 2015;313:23-24.

19. Agrawal S, Brown D. The Physician Payments Sunshine Act-two years of the open payments program. N Engl J Med 2016;374:906-909. 